\title{
Entre potestad soberana y derecho humano: la nacionalidad en el sistema americano
}

\author{
Fernando Arlettaz*
}

\begin{abstract}
RESUMEN
El Derecho Internacional clásico fundó la regulación de la nacionalidad sobre la base de dos principios. En primer lugar, todo individuo tiene una nacionalidad, y solo una. En segundo lugar, corresponde a cada Estado determinar quiénes son sus nacionales. El Derecho Internacional contemporáneo, en cambio, reconoce la nacionalidad como derecho del individuo e impone a los Estados, en algunos casos, el deber de otorgarla. El artículo muestra esta evolución en el contexto del derecho americano.
\end{abstract}

Nacionalidad - sistema interamericano - soberanía estatal

\author{
Between State power and Human Rights: \\ nationality in American International Law
}

\begin{abstract}
Classical International Law founded the regulation of nationality on the basis of two principles. First, everyone has one, and only one, nationality. Second, it is for each State to determine who its nationals are. Contemporary International Law, on the contrary, recognises nationality as a right of the individual and imposes on the States the duty to grant it in some cases. The article shows this evolution in the context of American law.
\end{abstract}

$$
\text { Nationality - inter-American system - state sovereignty }
$$

* Doctor en Sociología Jurídica e Instituciones Políticas, Universidad de Zaragoza. Investigador CONICET (Consejo Nacional de Investigaciones Científicas y Técnicas) / Universidad de Buenos Aires. Correo electrónico: fernandoarlettaz@yahoo.com.ar

Artículo recibido el 16 de enero de 2016 y aceptado para su publicación el 1 de marzo de 2017. 


\section{INTRODUCCIÓN}

$\mathrm{L}$ a distinción entre propios y extraños es la columna vertebral de cualquier organización política. En el contexto del Estado nacional, esta distinción adoptó la forma jurídica del binomio nacional-extranjero. El Derecho Internacional clásico fundó la regulación de este binomio sobre la base de dos principios. En primer lugar, todo individuo tiene una nacionalidad, y solo una. La apatridia y la múltiple nacionalidad son anomalías del sistema. En segundo lugar, corresponde a cada Estado determinar quiénes son sus nacionales. Ahora bien, entre estos dos principios existe, si no una contradicción, al menos una fuerte tensión. El recurso a un mecanismo de determinación unilateral de la nacionalidad incrementa, en efecto, el riesgo de que haya personas que sean reconocidas como nacionales por más de un Estado, o que no lo sean por ninguno. Diversas soluciones convencionales intentan entonces paliar esta situación, aunque sin alterar el principio básico de la potestad estatal en la materia.

El Derecho Internacional contemporáneo (entendiendo aquí por tal el que se desarrolla luego de la Segunda Guerra Mundial y que incluye el desarrollo del Derecho Internacional de los Derechos Humanos) continúa en parte la labor paliativa del Derecho Internacional clásico. Esto es particularmente evidente en relación con la apatridia. Pero el Derecho Internacional contemporáneo también reacciona contra dos rasgos del régimen de nacionalidad clásico. Por un lado, la múltiple nacionalidad, aunque no sea abiertamente promovida como solución general, no tiene ya el disfavor que tuvo en otras épocas. Por otro lado, aunque no se altera el principio de la potestad estatal en materia de nacionalidad, se reconoce que esta es un derecho del individuo y se impone al Estado, en algunos casos, el deber de otorgarla.

Este trabajo se basa en la hipótesis de que tal evolución se ha producido también en el Derecho Internacional americano. Sin embargo, esta transformación no ha significado un abandono total de los principios básicos del derecho de la nacionalidad así como se forjaron en el Derecho Internacional clásico. El paso de una perspectiva típicamente estatalista a una perspectiva influenciada por la filosofía de los Derechos Humanos ha conllevado una morigeración de la facultad soberana para definir quiénes son sus nacionales, pero no la erosión total de esta facultad. El artículo explorará esta hipótesis y, para ello, comenzará con una breve exposición general acerca de la nacionalidad en el Derecho Internacional.

\section{LA NACIONALIDAd EN EL DeRECho INTERnACIONAL}

Los juristas y filósofos políticos de la temprana modernidad se ocuparon de delimitar la distinción entre nacionales y extranjeros. En la tradición liberal contractualista, es bien conocido que el fundamento de la pertenencia a la comunidad política es el consentimiento. En la sociedad política lockeana, por ejemplo, los individuos que se encuentran en el estado de naturaleza no tienen entre sí ningún vínculo natural ni ninguna obligación unos con otros. La asociación política se constituye (y, eventualmente, 
se disuelve) mediante actos recíprocos de voluntad individual. Quienes toman parte en el contrato son miembros de la asociación política que se forma, es decir, ciudadanos ${ }^{1}$. Ahora bien, no es la voluntad individual aislada la que constituye el Estado, sino un conjunto de voluntades recíprocas. Mi declaración expresa y positiva de ser súbdito de un reino de nada servirá si los demás miembros de esa comunidad política no están dispuestos a aceptarme como su asociado. Para convertirme en ciudadano de un Estado debo ser aceptado en carácter tal por los demás ciudadanos o, lo que es lo mismo, por un acto de voluntad del soberano que los representa.

Serán los grandes juristas modernos, y en particular el suizo Emerich de Vattel, los que terminarán de delinear las bases del régimen de nacionalidad y extranjería que pervive, en sus líneas fundamentales, incluso en el Derecho Internacional contemporáneo. Ellos formularán el principio capital según el cual cada Estado decide quiénes son sus nacionales. Así, aunque Vattel cree que el ius sanguinis es el criterio más congruente con el derecho natural para transmitir la nacionalidad, admite que el soberano puede elegir otras vías para decidir quiénes son sus súbditos, naturalizando extranjeros u otorgando la nacionalidad a quienes hayan nacido en el territorio por el solo hecho de este nacimiento ${ }^{2}$.

Desde entonces, el Derecho Internacional ha concebido la nacionalidad como un atributo adquirido por el individuo a partir del ejercicio de una potestad estatal. La nacionalidad es, de acuerdo con la conocida definición de la Corte Internacional de Justicia en el caso Nottebohm, "un vínculo jurídico basado en un hecho social de conexión, en una efectividad solidaria de existencia de intereses y sentimientos, unido a una reciprocidad de derechos y deberes" ${ }^{3}$. Y, como reconoce la Corte en el mismo caso, es un criterio generalmente aceptado en Derecho Internacional que corresponde a cada Estado determinar quiénes son sus nacionales ${ }^{4}$.

${ }^{1}$ Locke, J., Second Treatise on Government, Harlan Davidson, Illinois, [1689]1982. Aunque los vocablos nacionalidad y ciudadanía no siempre se usan como sinónimos (y de hecho en muchos contextos es útil distinguirlos), los utilizamos aquí puntualmente de modo intercambiable para simplificar la discusión. Para un estudio más detallado ver Arlettaz, F., Extranjeros e inmigrantes: cuatro problemas de Derecho Internacional y Filosofía Jurídica, Lex Nova, Madrid, 2015.

${ }^{2}$ Vattel, E., Le droit des gens, ou príncipes de la loi naturelle appliqués à la conduite et aux affaires des nations, Société Typographique, Neuchatel, 1773.

${ }^{3}$ Corte Internacional de Justicia (CIJ), Nottebohm (Liechtenstein v. Guatemala), Deuxième phase: arrêt, Recueil, 1955, p. 23.

${ }^{4}$ Este es el criterio de la jurisprudencia internacional. Corte Permanente de Justicia Internacional (CPJI), Décrets de nationalité promulgués en Tunisie et au Maroc, Ser. B, no. 4, p. 24; CPJI, Questions de l'acquisition de la nationalité polonaise, Ser. B, no. 7, p. 16; CPJI, Échange des populations grecques et turques, Ser. B, no. 10, p. 21-23; CIJ, Nottebohm (Liechtenstein v. Guatemala), p. 20. El mismo criterio aparece en normas convencionales. Convention on certain questions relating to the conflict of nationality laws, La Haya, 12 de abril de 1930, LNTS vol. 179, no. 4137, artículo 1; European convention on nationality, Estrasburgo, 6 de noviembre de 1997, UNTS vol. 2135, no. I-37248, artículo 3. El criterio es confirmado por la doctrina. Ver, entre muchos otros, Balladore-Pallieri, G., La natura giuridica internazionale della potestà dello stato sugli individui, Torino, 1932; Bisschop, W. R., "Nationality in International Law", en The American Journal of International Law, vol. 37(2), 1943, pp. 320-325; Makarov, A. N., "Règles générales du droit de la nationalité", en Recueil des Cours, vol. 74, 1949, pp. 273 y ss.; Perrin, G., "Les conditions de validité de la nationalité en Droit International Public", en Recueil d'Études de Droit International en Hommage à Paul Guggenheim, Ginebra, 
El carácter unilateral del otorgamiento de la nacionalidad por parte del Estado hace que se generen puntos ciegos en el sistema: la apatridia y la doble nacionalidad. El Derecho Internacional ha concebido clásicamente el vínculo nacional como un vínculo exclusivo y necesario con un Estado: todo individuo tiene una nacionalidad, y no puede tener más de una. La apatridia es una falla del sistema, provocada no solo por actos arbitrarios de los Estados o dificultades de aplicación de las leyes, sino por la propia lógica del régimen de nacionalidad. Los conflictos de leyes son en efecto una fuente principalísima de ausencia de nacionalidad. La apatridia deja al individuo huérfano de todo vínculo político e impide el ejercicio a su respecto de las formas de protección que el Derecho Internacional reconoce que los Estados pueden ejercer a favor de sus nacionales. Es comprensible entonces que el Derecho Internacional repudie la apatridia como una anomalías.

La doble nacionalidad, aunque menos perjudicial desde el punto de vista del individuo, es también una falla teórica en el sistema. La nacionalidad es concebida por el Derecho Internacional clásico como un vínculo de lealtad y, como bien se sabe, nadie puede servir simultáneamente a dos señores. En el contexto del régimen de la protección diplomática, la doble nacionalidad puede provocar dudas acerca de cuál es el Estado legitimado para proteger al individuo. Igualmente, la doble nacionalidad puede tener inconvenientes prácticos para el propio individuo, como los relativos a la prestación de las obligaciones militares o a la determinación del punto de conexión cuando normas de conflicto del Derecho Internacional Privado utilizan la nacionalidad como criterio determinante ${ }^{6}$.

Los problemas que suscita la doble nacionalidad se resuelven por dos vías: previendo la pérdida de una de las nacionalidades o manteniendo la situación de doble nacionalidad

1968, pp. 853-888; Van Panhuys, H. F., The role of nationality in International Law: an outline, Leyden, 1969; Corriente, J. A., "La nacionalidad de las personas físicas ante el derecho internacional”, en Anuario de Derecho Internacional, vol. I, 1974, pp. 223-247; Hailbronner, K., "Nationality", en Aleinikoff, T. A., Chetail, V., Migration and International Legal Norms, Asser Press, La Haya, 2003; Sloane, R. D., "Breaking the Genuine Link: The Contemporary International Regulation of Nationality", en Harvard International Law Journal, vol. 50(1), 2009, pp. 1-60.

5 A fines del siglo XIX, el Instituto de Derecho Internacional declaró como principio en materia de nacionalidad que nadie debe carecer de ella (Instituto de Derecho Internacional, Principes relatifs aux conflits de lois en matière de nationalité (naturalisation et expatriation), Cambridge, 1895, principio 1). En 1928 declaró igualmente que ningún Estado debe aplicar reglas que tendrían como consecuencia la ausencia de nacionalidad si los otros Estados aceptasen las mismas reglas (Instituto de Derecho Internacional, $L a$ nationalité, Estocolmo, 1928, artículo 1). La ya citada Convention on certain questions relating to the conflict of nationality laws de 1930 recuerda, en su preámbulo, el interés general de la comunidad internacional en que cada individuo tenga una nacionalidad.

${ }^{6}$ Los mismos reparos que se formulan a la apatridia son dirigidos a la doble nacionalidad. El Instituto de Derecho Internacional sostuvo como principio general que nadie puede tener simultáneamente dos nacionalidades (Instituto de Derecho Internacional, Principes relatifs aux conflits de lois en matière de nationalité (naturalisation et expatriation), principio 2). Y luego agregó que ningún Estado debe aplicar reglas que tendrían como consecuencia la doble nacionalidad si los otros Estados aceptasen las mismas reglas (Instituto de Derecho Internacional, La nationalité, artículo 1). ). La ya citada Convention on certain questions relating to the conflict of nationality laws de 1930 señala el interés en que cada individuo tenga una y solo una nacionalidad. 
junto con un criterio para determinar cuál de las nacionalidades ha de considerarse prevalente en una situación concreta. Ambas vías pueden adoptarse tanto en el plano del derecho interno como en el plano del Derecho Internacional. En el plano del derecho interno responden al problema de la doble nacionalidad, por ejemplo, las reglas que determinan la pérdida de la nacionalidad por la adquisición de una nueva, así como aquellas que establecen que quienes son nacionales del Estado son siempre considerados como tales, aunque tengan además una segunda nacionalidad. Las mismas reglas respecto de pérdida de nacionalidad o establecimiento de una nacionalidad prevalente se encuentran en el Derecho Internacional convencional. Igualmente, la jurisprudencia ha desarrollado el criterio según el cual, en caso de conflictos suscitados por la doble nacionalidad, ha de prevalecer la nacionalidad efectiva, es decir, aquella que represente los vínculos reales más estrechos entre el individuo y uno de los Estados involucrados ${ }^{7}$. Los problemas suscitados por la apatridia son de más difícil solución. En efecto, en tal caso la única opción posible es la de otorgar una nacionalidad al individuo.

El Derecho Internacional contemporáneo, marcado por la filosofía de los Derechos Humanos, mantiene el principio de que son los Estados los que deciden quiénes son sus nacionales. Sin embargo, incorpora un elemento nuevo: el derecho a tener una nacionalidad $^{8}$. Ahora bien, aunque se dispone de modo general que toda persona tiene derecho a una nacionalidad, no se especifica cómo se ha de hacer efectivo ese derecho. En otras palabras: no se establece cuál es el Estado obligado a otorgar la nacionalidad para que el derecho tenga su cumplimiento. Esta distancia entre reconocimiento de un derecho y (ausencia de) reconocimiento de una obligación correlativa se ha ido llenando parcialmente mediante tratados internacionales más específicos, que imponen en algunos casos la obligación de otorgar una nacionalidad? .

\footnotetext{
${ }^{7}$ Corte Permanente de Arbitraje, Canevaro, La Haya, 3 de mayo de 1912; CIJ, Nottebohm (Liechtenstein v. Guatemala); Italian-United States Conciliation Commission, Strunsky-Mergé, Madrid, 10 de junio de 1955; Italian-United States Conciliation Commission, Flegenheimer, Ginebra, 20 de septiembre de 1958; Iran-United States Claim Tribunal, Nasser Esphahanian v. Tejarat Bank, La Haya, 29 de marzo de 1983. En el mismo sentido, la ya citada Convention on certain questions relating to the conflict of nationality laws de 1930, establece que, en un tercer Estado, la persona que posea varias nacionalidades deberá ser tratada como si no tuviese más que una, permitiendo al Estado reconocer, entre las múltiples nacionalidades posibles, bien la nacionalidad del país en el que tiene su residencia habitual y principal, bien la nacionalidad de aquel con el que, según las circunstancias, aparece más vinculado de hecho (artículo 5). El artículo 4 de la European convention on nationality estipula que el derecho de un Estado relativo a la determinación de quiénes son sus nacionales será aceptado por los demás Estados en la medida en que sea consistente con los tratados internacionales aplicables, el derecho consuetudinario y los principios de derecho generalmente reconocidos en materia de nacionalidad. Para una crítica del criterio de nacionalidad efectiva ver Sloane, R. D., "Breaking the Genuine Link: The Contemporary International Regulation of Nationality”.

${ }^{8}$ Ver al respecto las normas citadas en las secciones 3, 4 y 5 de este trabajo. Acerca de las transformaciones del Derecho Internacional en materia de nacionalidad, ver Spiro P. J., "An Emerging International Law of Citizenship?”, en American Society of International Law Proceedings, vol. 101, 2007, pp. 89-91; Lanfranchi, M.-P., "Les notions de nationalité et citoyenneté interrogées par le Droit International Public", en Lanfranchi, M.-P. et al. (dir.), Nationalité et citoyenneté, Bruylant, Bruxelles, 2012.

${ }^{9}$ Ver al respecto las normas citadas en las secciones 3,4 y 5 de este trabajo.
} 
Por otro lado, el Derecho Internacional contemporáneo, aunque mantiene el interés clásico en luchar contra las situaciones de apatridia, ha reducido su rechazo a las situaciones de doble nacionalidad. Es verdad que no hay un reconocimiento general a un derecho a la doble nacionalidad, pero existen disposiciones parciales que obligan a los Estados a conformarse a algunas situaciones de doble nacionalidad ${ }^{10}$.

\section{NACIONALIDAD Y POTESTAD SOBERANA}

Como dijimos al comienzo, nuestra hipótesis aquí es que la oscilación entre los dos polos mencionados (soberanía estatal prevalente en el Derecho Internacional clásico y derechos de los individuos reconocidos por el Derecho Internacional contemporáneo) se encuentran también en los instrumentos americanos relativos a la nacionalidad. Un conjunto de tratados (adoptados en las primeras décadas del siglo $\mathrm{XX}$ ) se refiere a la facultad estatal de conferir nacionalidad e intenta resolver los conflictos que pueden surgir del ejercicio unilateral y no coordinado de esta facultad. Tres son los instrumentos americanos más importantes de este periodo: la Convención que fija la condición de los ciudadanos naturalizados que renuevan su residencia en el país de su origen (Río de Janeiro, 1906) ${ }^{11}$, la Convención sobre nacionalidad (Montevideo, 1933) ${ }^{12}$ y la Convención sobre la nacionalidad de la mujer (Montevideo, 1933) ${ }^{13}$. Por otro lado, tanto la Declaración Americana de los Derechos y Deberes del Hombre ${ }^{14}$ como la Convención

${ }^{10}$ Ver al respecto las normas citadas en las secciones 3, 4 y 5 de este trabajo.

${ }^{11}$ Convención que fija la condición de los ciudadanos naturalizados que renuevan su residencia en el país de su origen, Río de Janeiro, 13 de agosto de 1906, Tercera Conferencia Internacional Americana, Serie OEA A-10. Son parte: Argentina, Chile, Colombia, Ecuador, El Salvador, Honduras, Nicaragua y Panamá. Brasil, Costa Rica, Guatemala y Estados Unidos eran parte pero denunciaron la Convención. Las ratificaciones deben comunicarse a Brasil (artículo III). En vigor según su artículo III. Puede ser denunciada por cualquier parte, teniendo la denuncia efecto luego de un año (artículos III y IV).

${ }^{12}$ Convención sobre nacionalidad, Montevideo, 26 de diciembre de 1933, Séptima Conferencia Internacional Americana, Serie OEA A-34. Son parte: Chile, Ecuador, Honduras, Panamá. Brasil y México eran parte pero denunciaron la Convención. Los instrumentos de ratificación y adhesión deben depositarse en la Unión Panamericana (artículos 8 y 11). En vigor según su artículo 9. La Convención tiene vigencia indefinida, pero puede ser denunciada en cualquier momento, teniendo efecto la denuncia un año después (artículo 10). Ella no afecta los compromisos adquiridos por los Estados en virtud de otros tratados (artículo 7).

${ }^{13}$ Convención sobre nacionalidad de la mujer, Montevideo, 26 de diciembre de 1933, Séptima Conferencia Internacional Americana, Serie OEA A-33. Son parte: Argentina, Brasil, Canadá, Chile, Colombia, Costa Rica, Cuba, Dominica, Ecuador, Estados Unidos, Guatemala, Honduras, Nicaragua, Panamá, Uruguay y Venezuela. Los instrumentos de ratificación y adhesión deben depositarse en la Unión Panamericana (artículos 2 y 5 ). Es según su artículo 3. La Convención tiene vigencia indefinida, pero puede ser denunciada en cualquier momento, teniendo efecto la denuncia un año después (artículo 4).

${ }^{14}$ Declaración Americana de los Derechos y Deberes del Hombre, Bogotá, 1948, IX Conferencia Internacional Americana. Los treinta y cinco Estados independientes de América son parte en la Organización de Estados Americanos y se hallan, por tanto, bajo la órbita de la Declaración. 
Americana de Derechos Humanos ${ }^{15}$ contienen disposiciones que aseguran el derecho a la nacionalidad. Así, mientras las convenciones incluidas en el primer grupo se basan en la idea de que es necesario coordinar el ejercicio de las soberanías estatales en materia de nacionalidad, los instrumentos de Derechos Humanos adoptan la perspectiva de la protección de la dignidad de la persona. Lo que mostraremos en este apartado y en los siguientes es cómo los instrumentos de Derechos Humanos imponen algunas limitaciones a la potestad soberana de determinar quiénes son miembros de la comunidad política sin anular totalmente la discrecionalidad estatal en este punto.

Las tres convenciones americanas en materia de nacionalidad que hemos mencionado más arriba, adoptadas en las primeras décadas del siglo XX, responden a la lógica estatalista. La Convención sobre nacionalidad de Montevideo (1933) tenía tres objetivos. Primero, evitar las situaciones de doble nacionalidad entre los países signatarios. Segundo, regular la cuestión de la nacionalidad en caso de transferencia de territorio. Tercero, establecer el carácter personal de la nacionalidad, es decir, que la adquisición o pérdida de la nacionalidad son situaciones que solo extienden sus efectos al individuo concernido, y no más allá. La Convención, sin embargo, no tuvo éxito. Esto queda en evidencia no solo por el reducido número de ratificaciones y las denuncias posteriores, sino por las importantes reservas formuladas por los Estados.

Respecto de lo primero, parece claro que el objetivo de la Convención era convertir a las nacionalidades americanas en mutuamente excluyentes ${ }^{16}$, en plena coherencia con la concepción clásica de la nacionalidad como vínculo único con un Estado. La Convención dispuso que "la naturalización ante las autoridades competentes de cualesquiera de los países signatarios implica la pérdida de la nacionalidad originaria” (artículo 1). Para hacer efectiva la disposición, el Estado de la nueva nacionalidad debe comunicar la naturalización al Estado de la nacionalidad de origen (artículo 2) ${ }^{17}$. Más allá de la escasa

${ }^{15}$ Convención Americana de Derechos Humanos, San José, 22 de noviembre de 1969, UNTS vol. 1144, no. I-17955. Son parte: Argentina, Barbados, Bolivia, Brasil, Chile, Colombia, Costa Rica, Dominica, Ecuador, El Salvador, Granada, Guatemala, Haití, Honduras, Jamaica, México, Nicaragua, Panamá, Paraguay, Perú, República Dominicana, Surinam, Uruguay. Eran parte pero la han denunciado: Trinidad y Tobago, Venezuela. La ha firmado pero no es parte: Estados Unidos.

${ }^{16}$ La misma finalidad seguiría años más tarde, en Europa, la Convention on reduction of cases of multiple nationality and military obligations in cases of multiple nationality, Estrasburgo, 6 de mayo de 1963, UNTS vol. 634, no. I-9065, que establece mecanismos para la pérdida de una de las nacionalidades en casos de nacionalidad múltiple, entre ellos la pérdida de la antigua nacionalidad por naturalización en otro Estado parte. Ver también el Protocolo de 1977 (Protocol amending the convention on reduction of cases of multiple nationality and military obligations in cases of multiple nationality, Estrasburgo, 24 de noviembre de 1977, UNTS vol. 1496, no. A-9065). La evolución reciente, en cambio, muestra una mayor aceptación de los casos de doble nacionalidad. Ver en este sentido el segundo Protocolo modificativo (Second protocol amending the convention of 6 May 1963 , Estrasburgo, de 2 de febrero de 1993, UNTS vol. 1967, no. A-9065) que prácticamente invierte la regla de la pérdida de la nacionalidad en algunos casos. La European convention on nationality también permite la doble nacionalidad en algunos casos.

${ }^{17}$ Uruguay, que nunca ratificó la Convención, formuló reserva a su artículo 1 al momento de firmarla, por no ser conforme a la legislación interna uruguaya. La República Dominicana, que tampoco ratificó la Convención, formuló reservas a sus artículos 1 y 2 al momento de firmarla, ya que según su Constitución de entonces ningún dominicano podía alegar su condición de extranjero. Honduras, al ratificar la Convención, 
efectividad real del régimen de la Convención sobre nacionalidad, su simple formulación muestra la existencia de un cierto consenso respecto de la irregularidad que suponía la posesión de más de una nacionalidad ${ }^{18}$.

Según el artículo 3 de la Convención sobre nacionalidad, el régimen de pérdida de nacionalidad por naturalización en otro país americano no derogaba ni modificaba el régimen de la Convención sobre la condición de los ciudadanos naturalizados que renuevan su residencia en el país de su origen (Río de Janeiro, 1906). Esta Convención, en efecto, perseguía el mismo objetivo: evitar las situaciones de doble nacionalidad. De acuerdo con su artículo I, "si un ciudadano nativo de cualquiera de los países firmantes de la presente Convención, y naturalizado en otro de estos, renovase su residencia en el país de su origen, sin intención de regresar a aquel en el que se hubiera naturalizado, se considerará que reasumió su ciudadanía originaria, y que renuncia a la ciudadanía adquirida por dicha naturalización”. Esta disposición había de considerarse aplicable a los ciudadanos ya naturalizados al momento de su adopción como a los que se naturalizarán después (artículo I). Igualmente, se incluía una presunción iuris tantum de que no existe intención de regresar al país de la naturalización si la persona reside en el país de origen por más de dos años (artículo II). Ambas convenciones pueden verse como complementarias: según la Convención de Montevideo, quien adquiere una nueva nacionalidad pierde la antigua; según la Convención de Río de Janeiro, quien vuelve a residir en el país de su nacionalidad nativa recupera la antigua nacionalidad perdida. La plena efectividad de este mecanismo de ida y vuelta depende sin embargo de que los Estados involucrados en un determinado caso sean parte en ambas convenciones o que, sin serlo, apliquen unilateralmente las mismas soluciones.

El segundo objetivo de la Convención sobre nacionalidad se materializó en su artículo 4, según este, en caso de transferencia de una porción de territorio de uno de los Estados signatarios a otro "los habitantes del territorio transferido no deben considerarse como nacionales del Estado a que se transfiere, a no ser que opten expresamente por cambiar su nacionalidad originaria”. No resulta claro si este artículo confería un derecho a cambiar de nacionalidad o si solo permitía esa posibilidad a condición de que el Estado que adquiere jurisdicción respecto del territorio otorgara la opción. Teniendo en cuenta el contexto de la adopción de la Convención, esta última parece la posibilidad más plausible ${ }^{19}$.

El tercer objetivo de la Convención sobre nacionalidad, establecer el carácter personal de la nacionalidad, se hizo efectivo mediante las disposiciones de los artículos 5 y 6.

\footnotetext{
formuló una reserva al artículo 1, ya que según la Constitución hondureña "ningún hondureño nacido en el territorio de la nación podrá tener otra nacionalidad distinta de la de Honduras, mientras resida en el país”. La denuncia de la Convención por parte de México se debió a la reforma constitucional de 1997, según esta, no se produce la pérdida de la nacionalidad mexicana por nacimiento por la adquisición de otra nacionalidad.

${ }^{18}$ Las reglas sobre derecho aplicable en materia de nacionalidad del tratado de Derecho Internacional Privado conocido como Código Bustamante van en el mismo sentido. Convención de Derecho Internacional Privado, La Habana, 20 de febrero de 1928, UNTS vol. 56, no. LON-1750.

${ }^{19}$ Ver, en el contexto europeo, la Council of Europe convention on the avoidance of statelessness in relation to State succession, Estrasburgo, 19 de mayo de 2006, UNTS vol. 2650, no. I-47197.
} 
Por un lado, "la naturalización confiere la nacionalidad solo a la persona naturalizada, y la pérdida de la nacionalidad, sea cual fuere la forma en que ocurra, afecta solo a la persona que la ha perdido"; y, por otro, "ni el matrimonio ni su disolución afectan a la nacionalidad de los cónyuges o de sus hijos" ${ }^{20}$. Estas disposiciones implican ya una aproximación a la concepción actual que se preocupa por la nacionalidad en relación con el individuo.

En la misma línea se ubica la Convención sobre la nacionalidad de la mujer (Montevideo, 1933), cuyo artículo 1 dispone que "no se hará distinción alguna, basada en sexo, en materia de nacionalidad, ni en la legislación ni en la práctica”. Aunque su título indica que el objetivo es evitar la discriminación contra la mujer, la lectura literal de su texto podría ser aplicable a cualquier caso de discriminación basada en sexo. Además, aunque el objetivo fundamental pudo haber sido evitar la discriminación contra la mujer al momento del matrimonio, su texto también permite oponerse a otras formas de discriminación basada en el sexo (como por ejemplo, la transmisión de la nacionalidad por ius sanguinis solo por vía paterna, y no materna) ${ }^{21}$. Más adelante volveremos acerca de la cuestión de la prohibición de discriminación en materia de nacionalidad.

\section{Nacionalidad y Derechos Humanos}

\subsection{Los instrumentos interamericanos}

Como hemos dicho en la Introducción, los dos principales instrumentos del sistema interamericano de Derechos Humanos contienen normas sobre la nacionalidad. La concepción del vínculo nacional que subyace a estos instrumentos es la que ha sido forjada por el Derecho Internacional clásico. Como ha dicho la Corte Interamericana, la nacionalidad es un "vínculo jurídico político que liga una persona a un Estado

${ }^{20}$ México, que luego denunciaría la Convención, formuló reservas a los artículos 5 y 6 . Brasil, al adherir a la Convención, formuló una reserva para mantener el sistema de naturalizaciones tácitas, que permite la naturalización de los menores sin que medie su solicitud individual. Honduras formuló reserva a los artículos 5 y 6 , por estar en desacuerdo con las disposiciones de su Código Civil que regulan las relaciones de familia. La República Dominicana también formuló reserva al artículo 6, sosteniendo que "no afecta la disposición constitucional vigente para la mujer dominicana que se case con extranjero". El Salvador, que nunca ratificó la Convención, había formulado una reserva al aprobarse su texto, según esta, la Convención solo podría ser ratificada una vez modificada la legislación interna sobre extranjería.

${ }^{21}$ México, que luego denunciaría la Convención, formuló una reserva para mantener en vigor su disposición constitucional según la cual la mujer extranjera que se case con mexicano queda naturalizada por virtud de la ley siempre que tenga o establezca su domicilio dentro del territorio nacional. El Salvador, que nunca ratificó la Convención, formuló una reserva en el sentido de que la ratificación solo sería posible una vez modificada su ley de extranjería. Los Estados Unidos formularon una reserva de acuerdo con la Convención que está sujeta a la acción del Congreso. Haití firmó la Convención con la enigmática frase "con reservas” y nunca la ratificó. Honduras firmó la Convención con las "reservas y limitaciones que determinen la Constitución y las leyes" del país. 
determinado" ${ }^{22}$. Más aún: la Corte acepta el principio básico del Derecho Internacional clásico de que todo individuo debe tener una nacionalidad: "la nacionalidad, conforme se acepta mayoritariamente, debe ser considerada como un estado natural del ser humano. Tal estado es no solo el fundamento mismo de su capacidad política sino también de parte de su capacidad civil" 23 .

No obstante que tradicionalmente se ha aceptado que la regulación de la nacionalidad es una competencia soberana, la evolución histórica muestra que el Derecho Internacional impone ciertos límites a la discrecionalidad de los Estados ${ }^{24}$. Sin embargo, decir que la definición de la nacionalidad no es una simple prerrogativa estatal no es lo mismo que decir que la definición de la nacionalidad no es en absoluto una prerrogativa estatal. Esto último, obviamente, no es correcto. Dentro de los márgenes que el Derecho Internacional impone a los Estados, estos pueden determinar las condiciones de adquisición originaria y derivada de la nacionalidad ${ }^{25}$. Igualmente, y dentro de esos mismos márgenes, los Estados pueden determinar los requisitos para cambiar de nacionalidad y los casos en que la nacionalidad se pierde.

En este sentido, el artículo XIX de la Declaración Americana establece: "Toda persona tiene derecho a la nacionalidad que legalmente le corresponde, y el de cambiarla, si así lo desea, por la de cualquier otro país que esté dispuesto a otorgársela”. Por su parte, el artículo 20 de la Convención reconoce el derecho a la nacionalidad en los siguientes términos: "1. Toda persona tiene derecho a una nacionalidad. 2. Toda persona tiene derecho a la nacionalidad del Estado en cuyo territorio nació si no tiene derecho a otra. 3. A nadie se privará arbitrariamente de su nacionalidad ni del derecho a cambiarla”.

Las distintas facetas del derecho a la nacionalidad, como están previstas en la Convención Americana y en la Declaración Americana, tienen un contenido limitativo

${ }^{22}$ Corte Interamericana de Derechos Humanos (Corte IDH), Propuesta de modificación a la Constitución política de Costa Rica relacionada con la naturalización, opinión consultiva OC-4/84 de 19 de enero de 1984, serie A no. 4, párr. 35; Corte IDH, Ivcher Bronstein vs. Perú, fondo, reparaciones y costas, sentencia de 6 de febrero de 2001, serie C no. 74, párr. 91; Corte IDH, Niñas Yean y Bosico vs. República Dominicana, excepciones preliminares, fondo, reparaciones y costas, sentencia de 8 de septiembre de 2005, serie C no. 130, párr. 136; Corte IDH, Personas dominicanas y haitianas expulsadas, excepciones preliminares, fondo, reparaciones y costas, sentencia de 28 de agosto de 2014, serie A no. 282, párr. 253.

${ }^{23}$ Corte IDH, Propuesta de modificación a la Constitución política de Costa Rica relacionada con la naturalización, párr. 32; Corte IDH, Ivcher Bronstein, párr. 86; Corte IDH, Niñas Yean y Bosico, párr. 138; Corte IDH, Personas dominicanas y haitianas expulsadas, párr. 255.

${ }^{24}$ Corte IDH, Propuesta de modificación a la Constitución política de Costa Rica relacionada con la naturalización, párr. 32; Corte IDH, Ivcher Bronstein, párr. 88; Corte IDH, Niñas Yean y Bosico, párr. 138; Corte IDH, Personas dominicanas y haitianas expulsadas, párr. 255.

25 Comisión Interamericana de Derechos Humanos (Comisión IDH), Informe anual de la Comisión Interamericana de Derechos Humanos 2005, OEA/Ser.L/V/II.124 Doc. 7, 27 febrero 2006, párr. 155; Comisión IDH, Robelo González, informe no. 25/01, caso 12.144 (Nicaragua), 5 de marzo de 2001, párr. 49; Corte IDH, Propuesta de modificación a la Constitución política de Costa Rica relacionada con la naturalización, párr. 32-36; Corte IDH, Ivcher Bronstein, párr. 88; Corte IDH, Niñas Yean y Bosico, párr. 140; Corte IDH, Personas dominicanas y haitianas expulsadas, párr. 256. 
de la soberanía estatal ${ }^{26}$. Sin embargo, no alteran el principio jurídico fundamental según el cual cada Estado determina discrecionalmente los criterios de adquisición, cambio y pérdida de la nacionalidad. En estas dos disposiciones aparecen diferentes derechos, que aunque están relacionados entre sí, son conceptualmente distintos ${ }^{27}$. En primer lugar, la Convención menciona el derecho a tener una nacionalidad. Se trata del derecho a la nacionalidad en abstracto, es decir, el derecho a tener una nacionalidad y no el derecho a tener una nacionalidad concreta. Es lo que podríamos llamar el derecho genérico a tener una nacionalidad. La Declaración hace una formulación de este derecho que deja en claro la importancia de la soberanía estatal: no se trata simplemente del derecho a tener una nacionalidad, sino del derecho de tener la nacionalidad que legalmente corresponda ${ }^{28}$.

En segundo lugar, la Convención (pero no la Declaración) reconoce el derecho a tener una nacionalidad concreta. Se trata del derecho a tener la nacionalidad del Estado en el que se ha nacido, si no se tiene derecho a otra. Es lo que podríamos llamar el derecho concreto a tener una nacionalidad. El derecho genérico a tener una nacionalidad no implica un correlativo deber del Estado de otorgar esa nacionalidad a todo ser humano, ni siquiera un deber del Estado de otorgar esa nacionalidad a todo ser humano que de otro modo se vería en situación de apatridia. El deber impuesto por la Convención respecto del otorgamiento de la nacionalidad es más limitado: solo existe un deber de otorgar la nacionalidad a las personas que habiendo nacido en el territorio del Estado no tienen derecho a otra nacionalidad.

En tercer lugar se menciona el derecho a no ser privado arbitrariamente de la nacionalidad. De la redacción del precepto surge que no es ilegítimo que alguien sea privado de su nacionalidad, siempre que esta privación no sea arbitraria. El derecho aparece mencionado solo en la Convención, pero no en la Declaración, aunque la Comisión lo ha considerado implícito en esta última ${ }^{29}$.

En cuarto lugar se menciona el derecho a cambiar de nacionalidad, tanto en la Declaración como en la Convención. Sin embargo, ya que no hay un derecho a obtener una nacionalidad determinada (salvo en el supuesto concreto que ya hemos señalado), el derecho a cambiar de nacionalidad no debe interpretarse como el derecho a obtener una determinada nacionalidad, sino como el derecho a que no se pongan obstáculos

${ }^{26}$ Rodríguez, M. F., "El derecho a la nacionalidad", en Revista Internacional de Derechos Humanos, vol. 1, 2011, p. 87.

${ }^{27}$ Ver una conceptualización parecida a la que aquí hacemos en O’Donnell, D., Derecho Internacional de los Derechos Humanos, México, Oficina del Alto Comisionado de las Naciones Unidas para los Derechos Humanos, 2012, p. 600.

${ }^{28}$ Según la Convención, la apatridia resulta una situación teóricamente ilícita, lo que no sucede en el caso de la Declaración, ya que si a una persona no le corresponde ninguna nacionalidad según la legislación vigente, no hay tampoco derecho a la nacionalidad. Sin embargo, teniendo en cuenta lo que se dirá sobre la ausencia de un deber específico de reconocimiento en cabeza de un Estado derivado del primer inciso del artículo 20 de la Convención, las consecuencias prácticas de ambos instrumentos son idénticas.

${ }^{29}$ Comisión IDH, Informe sobre la situación de los Derechos Humanos en Chile 1990 (OEA/Ser.L/V/II.77. rev. 1 Doc. 18, 8 de mayo de 1990), derecho a la nacionalidad, párr. 1. 
arbitrarios a la obtención de una nacionalidad cuando exista un Estado que esté dispuesto a darla (como literalmente dice la Declaración) ${ }^{30}$.

A la luz de estos preceptos, nuestra hipótesis inicial parece hasta ahora correcta: el derecho concreto a tener una nacionalidad tiene un campo de aplicación bien delimitado; y el derecho abstracto a tener una nacionalidad solo resulta operativo en los términos definidos por la respectiva legislación nacional. En el mismo sentido, la prohibición de privar a alguien arbitrariamente de su nacionalidad no hace imposible una privación justificada y el derecho a cambiar de nacionalidad no impone a ningún Estado la obligación de dar su nacionalidad si no quiere hacerlo. Las restricciones a la soberanía estatal emergentes del Derecho Internacional de los Derechos Humanos no alteran el núcleo duro del régimen internacional de la nacionalidad.

\subsection{Un derecho a la nacionalidad}

Como ya mencionamos, el primer derecho reconocido por la Declaración y la Convención Americanas es el derecho genérico a tener una nacionalidad ${ }^{31}$. Sin embargo, la estructura jurídica de este derecho es diferente de la de otros derechos: el derecho a la libertad de expresión, por ejemplo, obliga al Estado a reconocer la libertad de expresión a toda persona que se encuentre bajo su jurisdicción. El derecho genérico a tener una nacionalidad, en cambio, no impone a un Estado concreto el deber de otorgar su nacionalidad a cualquier persona que la solicite, ni a cualquier persona que se halle bajo su jurisdicción. Sin embargo, el enunciado genérico del derecho a la nacionalidad no resulta vacío de contenido ${ }^{32}$.

La primera consecuencia del derecho genérico a tener una nacionalidad es la obligación de reconocer la nacionalidad que se posee. Esto implica una obligación de los Estados de dotar de efectos jurídicos reales a la nacionalidad efectivamente poseída por una persona. En el caso de las Personas dominicanas y haitianas expulsadas, la Corte

${ }^{30}$ O’Donnell, D., Derecho Internacional de los Derechos Humanos, p. 606. Para un estudio más detallado sobre el derecho a la nacionalidad en los antecedentes interamericanos, ver Arlettaz, F., "La nacionalidad en el Derecho Internacional americano”, en Anuario Mexicano de Derecho Internacional, vol. XV, 2015, pp. 413-447.

31 El derecho genérico a la nacionalidad aparece reconocido en un gran número de declaraciones y tratados. Artículo 15.1, Declaración Universal de Derechos Humanos, Resolución 217 A (III), de 10 de diciembre de 1948; artículo 24.3, Pacto Internacional de Derechos Civiles y Políticos, Nueva York, 16 de diciembre de 1966, UNTS vol. 999, no. I-14668 (derecho del niño a adquirir una nacionalidad); artículo 7, Convención sobre los derechos del niño, Nueva York, 2 de septiembre de 1990, UNTS vol. 1577, no. I-27531; artículo 29, Convención internacional sobre la protección de los derechos de todos los trabajadores migratorios y de sus familiares, Nueva York, 18 de diciembre de 1990, UNTS vol. 2220, I-39481 (derecho de los hijos de los trabajadores migratorios a tener una nacionalidad); artículo 4, European convention on nationality; artículo 7, African Charter on the Rights and Welfare of the Child, 11 de julio de 1990, OAU Doc. CAB/LEG/24.9/49 (1990).

${ }^{32}$ Se ha señalado que se trataría de un enunciado genérico, que resulta violado cuando se viola alguno de los otros aspectos del derecho a la nacionalidad (derecho concreto a tener una nacionalidad, privación arbitraria de nacionalidad, etc.). Lavopa, F., “Artículo 20. Derecho a la nacionalidad”, en Alonso Regueira, E. (coord.), La Convención Americana de Derechos Humanos y su proyección en derecho argentino, Universidad de Buenos Aires, Buenos Aires, 2013, p. 339. 
Interamericana declaró que no dar la posibilidad a alguien de que presente los documentos que lo identifican como nacional (dominicano, en la especie), o destruir esos documentos, conlleva una violación del derecho a la nacionalidad ${ }^{33}$. El caso era, de alguna manera, un caso fácil, en el sentido de que el desconocimiento de la nacionalidad se había producido por el propio Estado que la había otorgado. La cuestión deviene mucho más compleja si de lo que se trata es de saber en qué casos un Estado puede desconocer la nacionalidad otorgada por otro Estado. En línea de principio, este desconocimiento resulta posible. Nuestra conjetura es que un Estado puede desconocer la nacionalidad otorgada por un tercer Estado en la medida en que tal desconocimiento no sea arbitrario. Por ejemplo, es generalmente admitido que un Estado no está obligado a reconocer, en el caso de personas con doble nacionalidad, una nacionalidad que no sea efectiva ${ }^{34}$.

La segunda consecuencia del derecho genérico a la nacionalidad tiene que ver con la razonabilidad en la interpretación del derecho interno. Aunque el Estado puede definir cuáles son las circunstancias que determinan la adquisición y la pérdida de su nacionalidad, tales circunstancias deben ser establecidas con anterioridad, de forma objetiva y clara por la autoridad competente; además, la interpretación de los criterios fijados debe ser razonable. Por supuesto, esto no impide que un Estado tenga políticas restrictivas en materia de nacionalidad, siempre que esas políticas se ajusten a los criterios formales de previsibilidad, objetividad y claridad.

Los dos casos relativos a las personas de origen haitiano residentes en la República Dominicana son particularmente ilustrativos. De acuerdo con el régimen constitucional dominicano vigente hasta 2010, eran dominicanas todas las personas nacidas en territorio dominicano, con excepción de aquellas personas cuyos padres estuvieran en tránsito en el país. La interpretación de la expresión en tránsito por parte de los órganos administrativos y judiciales había sido muy heterogénea, en particular en lo relativo a si las personas que residían de modo permanente pero irregular en el país podían considerarse en tránsito. La imprecisión en la interpretación del régimen legal afectaba en gran escala a los haitianos residentes en la República Dominicana. En 2010, una reforma constitucional agregó una nueva excepción según la cual tampoco serían dominicanos los hijos de extranjeros en situación administrativa irregular. Entretanto, una sentencia de la Corte Suprema de 2005 y una sentencia del Tribunal Constitucional de 2013 declararon que, incluso respecto de los nacidos antes de la reforma de 2010, se debía excluir de la nacionalidad dominicana a las personas cuyos padres estuvieran en situación administrativa irregular, ya que la expresión en tránsito debía interpretarse en el sentido de incluir a los extranjeros en situación administrativa irregular. En consecuencia, el Tribunal Constitucional ordenó revisar todos los actos de otorgamiento de nacionalidad dominicana desde 1929.

En el caso Niñas Yean y Bosico (caso anterior a la reforma de 2010 y a las dos sentencias judiciales mencionadas) la Corte Interamericana sostuvo que al utilizar el criterio

33 Corte IDH, Personas dominicanas y haitianas expulsadas, párr. 273-274.

${ }^{34}$ Ver lo que se dice sobre la nacionalidad efectiva en la sección 2. De la misma manera, si un Estado no reconoce la existencia de otro Estado puede también desconocer la nacionalidad invocada por los (alegados) nacionales de ese Estado. 
de la residencia en tránsito el Estado debe respetar un límite temporal razonable, de modo que un extranjero que desarrolla vínculos en un Estado no puede ser equiparado a un transeúnte o a una persona en tránsito ${ }^{35}$. El criterio fue reafirmado en el caso de las Personas dominicanas y haitianas expulsadas ${ }^{36}$. Aquí se agregó además un elemento nuevo, al decir que la denegación de la nacionalidad dominicana sobre la base de un criterio interpretativo adoptado con posterioridad al nacimiento de las personas interesadas implica una vulneración de la seguridad jurídica que conlleva una violación del derecho a la nacionalidad ${ }^{37}$.

La Corte ha dicho que el derecho a tener una nacionalidad impone a los Estados el deber de evitar la apatridia ${ }^{38}$, absteniéndose de adoptar prácticas o legislación, respecto del otorgamiento de la nacionalidad, cuya aplicación favorezca el incremento del número de personas apátridas ${ }^{39}$. Esta amplia afirmación, sin embargo, poco avanza acerca de los medios concretos que se han de poner en movimiento para la lucha contra las situaciones de apatridia. En efecto, ¿qué quiere decir favorecer el incremento de personas apátridas? Por definición, cualquier sistema de otorgamiento unilateral de nacionalidad crea un riesgo de incremento de personas apátridas. En nuestra opinión, esta afirmación de la Corte solo tiene sentido si se la lee en conjunción con lo ya dicho: los Estados pueden establecer libremente (dentro de ciertos límites) los criterios para otorgar la nacionalidad, pero deben adoptar todas las medidas necesarias para que quienes según esos criterios tienen derecho a acceder a la nacionalidad puedan efectivamente hacerlo ${ }^{40}$.

Esto muestra que el sistema internacional sigue funcionando, en materia de nacionalidad, como una constelación de elementos solo parcialmente coordinados entre sí. En efecto, el deber de evitar la apatridia no implica el deber de resolver las situaciones de apatridia generadas por otros. No es incompatible con el deber de evitar la apatridia

35 Corte IDH, Niñas Yean y Bosico, párr. 157. La misma interpretación en Comisión IDH, Informe sobre la situación de los Derechos Humanos en República Dominicana 1999, OEA/Ser.L/II.104 doc. 49 rev. 1, 7 de octubre de 1999, párr. 363.

${ }^{36}$ Corte IDH, Personas dominicanas y haitianas expulsadas, párr. 294.

${ }^{37}$ Corte IDH, Niñas Yean y Bosico, párr. 298.

${ }^{38}$ Corte IDH, Propuesta de modificación a la Constitución política de Costa Rica relacionada con la naturalización, párr. 34; Corte IDH, Niñas Yean y Bosico, párr. 139-140; Corte IDH, Personas dominicanas y haitianas expulsadas, párr. 257. A los apátridas de jure habría que sumar los apátridas de facto, es decir, los incapaces de demostrar su nacionalidad, y los desprovistos de una nacionalidad efectiva para los efectos de la protección internacional. Corte IDH, Niñas Yean y Bosico, voto concurrente del juez Cançado Trindade, párr. 11.

${ }^{39}$ Corte IDH, Niñas Yean y Bosico, párr. 142; Corte IDH, Personas dominicanas y haitianas expulsadas, párr. 257.

${ }^{40}$ Esto obviamente sin perjuicio de las obligaciones de luchar contra la apatridia que hayan adquirido los Estados con independencia de las normas interamericanas. La Convención para reducir los casos de apatridia, Nueva York, 30 de agosto de 1961, UNTS vol. 989, no. I-14458, establece un conjunto de reglas que buscan reducir los efectos negativos de los conflictos de leyes en materia de nacionalidad. Según el artículo 1.1: “Todo Estado contratante concederá su nacionalidad a la persona nacida en su territorio que de otro modo sería apátrida". Igualmente, según el artículo 4.1: "Todo Estado contratante concederá su nacionalidad a una persona que no haya nacido en el territorio de un Estado contratante y que de otro modo sería apátrida si en el momento del nacimiento del interesado uno de los padres tenía la nacionalidad del primero de esos Estados". En ambos casos se permiten excepciones. Ver más adelante el derecho concreto a la nacionalidad. 
el hecho de que un Estado imponga requisitos exigentes para adquirir la nacionalidad a un apátrida no nacido en su territorio, si la apatridia no está causada por ese mismo Estado. En la opinión consultiva sobre la reforma constitucional costarricense en materia de nacionalidad, se sostuvo que el hecho de que la legislación previera que la persona que se casara con un nacional y perdiera su nacionalidad de origen debiera estar dos años casada y residiendo en el territorio del Estado de su cónyuge para naturalizarse en este no es contrario al artículo 20 de la Convención. En este caso la apatridia no está causada por el Estado que impone las exigentes condiciones de naturalización, sino por el Estado de la nacionalidad de origen que priva a los suyos de la nacionalidad por el hecho de casarse con extranjero ${ }^{41}$.

Finalmente, el derecho genérico a la nacionalidad, leído en conjunto con el artículo 8 de la Convención, implica que las garantías procesales reconocidas en esta última disposición son aplicables a los procedimientos administrativos relativos a la nacionalidad. En el asunto Ivcher Bronstein la Corte las aplicó a un proceso que había tenido por resultado la privación de la nacionalidad peruana adquirida por naturalización. En el caso, se había anulado el acto de naturalización por considerar la autoridad administrativa que habían existido irregularidades en el procedimiento de concesión de la nacionalidad. Sin embargo, la declaración de nulidad había tenido lugar tras algunas graves irregularidades procesales. La Corte declaró la violación de las reglas del debido proceso del artículo 8.1 y 8.2 de la Convención ${ }^{42}$. Si bien estos principios fueron establecidos en un caso de privación de nacionalidad, la Corte entiende que deben ser aplicadas a cualquier procedimiento en el que esté en juego la nacionalidad de la persona.

Respecto del derecho concreto a la nacionalidad, hemos visto que según el artículo 20.2 de la Convención Americana toda persona tiene derecho a la nacionalidad del Estado en el que ha nacido si no tuviere derecho a otra ${ }^{43}$. La Convención Americana sigue en este punto el criterio del ius soli, del mismo modo que lo hace la Convención para reducir los casos de apatridia como principio general. Sin embargo, a diferencia de esta última que prevé un complejo sistema de excepciones de las que pueden prevalerse los Estados, la Convención Americana establece el principio del ius soli sin excepción

41 Corte IDH, Propuesta de modificación a la Constitución política de Costa Rica relacionada con la naturalización, párr. 43-49.

42 Corte IDH, Ivcher Bronstein, párr. 106-110.

43 Según la Corte Interamericana, el artículo 20.2 de la Convención Americana debe interpretarse en el mismo sentido que lo establecido en el artículo 7 de la Convención sobre los Derechos del Niño (Corte IDH, Personas dominicanas y haitianas expulsadas, párr. 260). Esta remisión, sin embargo, no parece del todo adecuada, en la medida en que la Convención sobre los Derechos del Niño es menos específica que la Convención Americana y solo reconoce un derecho genérico a la nacionalidad. Es verdad que la Convención declara que el niño tiene derecho a la nacionalidad "desde que nace" (artículo 7.1), con lo que deja en claro que el deber de evitar la apatridia se produce desde el mismo nacimiento. Sin embargo, la Convención sobre los Derechos del Niño, a diferencia de la Convención Americana, no impone a ningún Estado la obligación de otorgar su nacionalidad, sino que remite a la legislación interna del Estado y a las obligaciones contraídas por estos con independencia de la propia Convención sobre Derechos del Niño (artículo 7.2). El artículo 8 declara el derecho del niño a preservar su identidad, incluyendo en ella su nacionalidad. 
en aquellos casos en los que la no aplicación de este criterio llevaría a una situación de apatridia $^{44}$.

Según la Corte, la condición del nacimiento en el territorio del Estado es la única a ser demostrada para la adquisición de la nacionalidad, en lo que se refiere a personas que no tendrían derecho a otra nacionalidad si no adquieren la del Estado en donde nacieron ${ }^{45}$. Por otra parte, los requisitos exigidos para probar el nacimiento en el territorio deben ser razonables y no pueden representar un obstáculo para acceder a la nacionalidad ${ }^{46}$. El deber de evitar apatridia se hace exigible para los Estados al momento del nacimiento de las personas ${ }^{47}$. Para cumplir su deber de no dejar a nadie en situación de apatridia, el Estado debe tener la certeza de que la niña o el niño nacido en su territorio, en forma inmediata después de su nacimiento, podrá efectivamente adquirir la nacionalidad de otro Estado ${ }^{48}$. De este modo, el Estado no puede prevalerse de una génerica afirmación de que en el Estado de la nacionalidad de los padres rige el ius sanguinis (como había hecho la República Dominicana en el caso de las Personas dominicanas y haitianas expulsadas ${ }^{49}$ ).

Un problema que no está resuelto por el texto de la Convención ni por la jurisprudencia interamericana es si el deber de evitar la apatridia otorgando la nacionalidad por ius soli resulta también exigible en casos de apatridia sobrevenida. Supongamos el siguiente caso: el señor $\mathrm{X}$, nacido en el territorio de $\mathrm{Y}$, adquiere la nacionalidad $\mathrm{Z}$ por ius sanguinis; pasados unos años, pierde la nacionalidad de Z. ¿Está Y obligado a otorgarle su nacionalidad para evitar la situación de apatridia? La solución no es clara. En principio, la respuesta parecería negativa, ya que en tal caso las consecuencias perjudiciales del acto de un Estado (en el ejemplo, el Estado Z que retira su nacionalidad a una persona sin verificar previamente si esta privación la deja en situación de apatridia) serían cargadas sobre las espaldas de otro Estado (el Estado Y, que debería otorgar su nacionalidad). Sin embargo, la filosofía protectoria del Derecho Internacional de los Derechos Humanos

${ }^{44}$ En el contexto europeo, el criterio adoptado para evitar una situación de apatridia fue en un primer momento el del ius sanguinis por vía materna. Ver artículo 1, Convention tendant à réduire le nombre des cas d'apatridie, Berna, 13 de septiembre de 1973, UNTS vol. 1081, no. I-16550. Más recientemente, la European convention on nationality adoptó el ius soli en su artículo 6. La African charter on the rights and welfare of the child, establece el criterio del ius soli como recurso para evitar la apatridia, en relación con los niños que de otro modo resultarían apátridas (artículo 7).

${ }^{45}$ Corte IDH, Niñas Yean y Bosico, párr. 156; Corte IDH, Personas dominicanas y haitianas expulsadas, párr. 260.

${ }^{46}$ Corte IDH, Niñas Yean y Bosico, párr. 171; Corte IDH, Personas dominicanas y haitianas expulsadas, párr. 470.

${ }^{47}$ Corte IDH, Niñas Yean y Bosico, párr. 174; Corte IDH, Personas dominicanas y haitianas, párr. 258. La Corte realiza esta afirmación para señalar que, a pesar de que el Estado reconoció tardíamente la nacionalidad que no había reconocido en un primer momento, tal reconocimiento tardío no borraba la violación ya producida. Aquí hallamos una diferencia con la Convención para reducir los casos de apatridia. Según esta última, en efecto, es posible que los Estados subordinen la adquisición de la nacionalidad a una solicitud del interesado, permitiéndose que la posibilidad de presentar esta solicitud se postergue hasta los 18 años de edad o que sea subordinada a la residencia previa en el territorio por un plazo de hasta 10 años.

${ }^{48}$ Corte IDH, Personas dominicanas y haitianas expulsadas, párr. 259.

${ }^{49}$ Corte IDH, Personas dominicanas y haitianas expulsadas, párr. 297. 
obliga a dar una respuesta positiva, respuesta que puede hallarse sin forzar el tenor literal del artículo 20 de la Convención ${ }^{50}$. Entendemos además que, debido a la aversión que el Derecho Internacional tiene por la apatridia, la respuesta positiva es independiente del hecho de que la privación de nacionalidad por parte de $\mathrm{Z}$ sea legal o ilegal ${ }^{51}$.

\subsection{Privación y cambio de nacionalidad}

El derecho a no ser privado arbitrariamente de la nacionalidad está relacionado con el derecho a tener una nacionalidad, pero no se identifica totalmente con él ${ }^{52}$. Podría haber una privación arbitraria de nacionalidad que no dejara al individuo en situación de apatridia (por ejemplo, porque se tratara de un individuo con doble nacionalidad que solo fuera privado de una de ellas). Habría en este caso violación del segundo aspecto del derecho, pero no del primero. También podría suceder que una persona fuera privada arbitrariamente de su nacionalidad, pero que le fuera asignada inmediatamente otra diferente. En este caso también habría una violación del derecho a no ser privado arbitrariamente de la nacionalidad, sin que hubiera una violación del derecho a tener una nacionalidad ${ }^{53}$.

En una terminología generalmente aceptada, la idea de privación de la nacionalidad tiene como presupuesto la posesión previa de la nacionalidad que se pierde. En esta categoría se incluye el ejemplo de la legislación chilena que permitía privar de nacionalidad

${ }^{50}$ Para una respuesta positiva en general (no en el derecho americano específicamente), ver Ganczer, M., “The Right to a Nationality as a Human Right?", en Hungarian Yearbook of International Law and European Law, 2014, p. 26.

${ }^{51}$ Cuestión diferente sería si la persona renunciara a la nacionalidad de Z con la intención de colocarse voluntariamente en situación de apatridia y, de este modo, adquirir la nacionalidad del país de nacimiento. Probablemente el ejemplo sea de laboratorio (para que la situación se diera realmente deberían combinarse la voluntad muy peculiar de un sujeto de hacerse apátrida y la conducta del Estado Z admitiendo una renuncia de nacionalidad que deriva en apatridia). Sin embargo, la respuesta (teórica) a este caso sería inversa a la anterior: el Derecho Internacional no reconoce al individuo un derecho a optar por la nacionalidad del país de nacimiento. Tal nacionalidad solo funciona como último recurso para evitar una indeseada situación de apatridia. Buscar voluntariamente esa apatridia sería una especie de fraude a la ley internacional.

52 La prohibición de privación arbitraria de nacionalidad aparece en el artículo 15 de la Declaración universal de Derechos Humanos. El artículo 7 de la European convention on nationality enumera los casos en los que los Estados pueden legítimamante privar a alguien de la nacionalidad que posee (adquisición de una nueva nacionalidad, fraude en la adquisición de la nacionalidad, servicio militar voluntario en una fuerza extranjera, conducta seriamente perjudicial a los intereses del Estado, ausencia de vínculo genuino entre el Estado y un individuo residiendo en el extranjero, cese en el cumplimiento de los requisitos para la adquisición ex lege por un menor, nueva nacionalidad de un menor adoptado). En todos estos casos, salvo el de fraude, la privación de naconalidad solo es posible si el individuo no deviene apátrida.

${ }^{53}$ Una pregunta de interés es si toda privación de nacionalidad que deja al individuo en situación de apatridia es arbitraria en los términos de esta disposición. Acerca del problema en general (no específicamente en el contexto del derecho interamericano), ver una respuesta positiva, en Ganczer, M., "The Right to a Nationality as a Human Right?", p. 31. Una respuesta negativa, en cambio, en Human Rights and Arbitrary Deprivation of Nationality, Report of the Secretary-General, 14 December 2009. UN Doc. A/HRC/13/34. La Convención para reducir los casos de apatridia prohíbe privar a alguien de su nacionalidad si esto lo convierte en apátrida, pero admite excepciones (artículo 8). 
en supuestos de estados de excepción o de emergencia y que la Comisión Interamericana consideró un supuesto de privación arbitraria ${ }^{54}$. Y también el caso Ivcher Bronstein, relativo a una persona a la que se le retiró la nacionalidad peruana en el contexto de un procedimiento lleno de irregularidades y en el que la Corte declaró que la privación de la nacionalidad había sido arbitraria en los términos del artículo 20 de la Convención ${ }^{55}$.

La Corte Interamericana ha ampliado el concepto de privación de nacionalidad hasta hacerlo comprensivo de supuestos en los que se deniega a una persona la nacionalidad a la que normalmente tendría derecho, pero que todavía no posee ${ }^{56}$. Por ejemplo, en el caso Gelman analizó la situación de una persona nacida mientras su madre (de nacionalidad argentina y residente en Argentina) se encontraba ilegalmente privada de su libertad en Uruguay. La recién nacida había sido entregada de modo irregular a una familia uruguaya, que la había inscrito como hija propia. La Corte declaró la existencia de una supresión de identidad que implicó la privación arbitraria de la nacionalidad de la niña ${ }^{57}$. Igualmente, en Niñas Yean y Bosico y en Personas dominicanas y haitianas expulsadas la Corte sostuvo que el hecho de no otorgar la nacionalidad a quien de acuerdo con el derecho interno o con el Derecho Internacional tiene derecho a adquirirla constituye una privación arbitraria de la nacionalidad ${ }^{58}$.

Un supuesto semejante al de la pérdida de nacionalidad es el de la llamada cuasipérdida de nacionalidad: el Estado declara, con efecto retroactivo, que una persona nunca ha tenido su nacionalidad, ya sea porque se modifican con efecto retroactivo los requisitos para considerar adquirida la nacionalidad, ya sea porque se declara con efecto retroactivo que una persona nunca ha reunido esos requisitos. Las normas que prohíben la privación arbitraria de la nacionalidad deben ser interpretadas como incluyendo también este supuesto, ya que de otro modo el Estado podría eludir el respeto del Derecho Internacional por la simple vía de establecer una ficción jurídica según la cual la persona nunca tuvo su nacionalidad 59 .

Este era uno de los puntos capitales a considerar en el caso de las Personas dominicanas y haitianas expulsadas, ya que dos sentencias judiciales de las más altas instancias habían interpretado restrictivamente y con carácter retroactivo los criterios para la obtención de la nacionalidad dominicana. Aunque ninguna de las víctimas reconocidas como tales por la Corte Interamericana había sido parte en los procesos que llevaron a esas sentencias, ni se le había aplicado directamente el criterio de las mismas privándolos efectivamente

${ }^{54}$ Comisión IDH, Informe sobre la situación de los Derechos Humanos en Chile 1977, OEA/Ser.L/V/II.40 Doc. 10, 11 febrero 1977, derecho a la nacionalidad, párr. 8; Comisión IDH, Informe sobre la situación de los Derechos Humanos en Chile 1990, conclusiones, párr. 17.

${ }^{55}$ Corte IDH, Ivcher Bronstein, párr. 106-110.

${ }^{56}$ Lavopa, F., “Artículo 20. Derecho a la nacionalidad”, p. 342, llega a la misma conclusión.

57 Corte IDH, Gelman vs. Uruguay, fondo y reparaciones, sentencia de 24 de febrero de 2011, serie A no. 222, párr. 127.

58 Corte IDH, Niñas Yean y Bosico, párr. 174. Corte IDH, Personas dominicanas y haitianas expulsadas, párr. 298 y 301.

${ }^{59}$ De Groot, G.-R., "Survey on Rules on Loss of Nationality in International Treaties and Case Law", en CEPS Papers on Liberty and Security in Europe, vol. 57, 2013, pp. 2-3. 
de su nacionalidad dominicana ${ }^{60}$, la Corte analizó el contenido de las mismas. Al respecto, sostuvo que las normas legales que, en aplicación de la sentencia del Tribunal Constitucional, mandan que las personas nacidas en territorio dominicano de padres extranjeros en situación irregular se inscriban en el registro de extranjeros (pudiendo acceder a un plan de regularización) resultan violatorias de la obligación convencional de adoptar disposiciones de derecho interno, en relación con el derecho a la nacionalidad. Ello así porque implican desconocer la nacionalidad dominicana a personas que deberían tenerla desde su nacimiento (y esto incluso si la referida normativa abre la posibilidad, por la vía de la regularización, a una naturalización posterior) ${ }^{61}$.

Veamos finalmente el derecho a cambiar de nacionalidad. Como ya se ha dicho, el derecho a cambiar de nacionalidad debe ser interpretado como el derecho a adquirir una nueva nacionalidad en el caso de que haya un Estado que esté dispuesto a otorgarla. El Estado de la antigua nacionalidad, así como terceros Estados, debe abstenerse de obstaculizar arbitrariamente esta adquisición ${ }^{62}$.

Ante la adquisición de una nueva nacionalidad, el Estado de la antigua nacionalidad podría retirar la nacionalidad previa: la adquisición de una nueva nacionalidad es fácilmente reconocible como una circunstancia que evitaría que tal retiro fuera calificado de arbitrario y además el individuo no quedaría en situación de apatridia. Lo que es más dudoso es si es posible argumentar que la adquisición de una nueva nacionalidad faculta al nacionalizado para reclamar a su antiguo Estado que le retire la nacionalidad previa. En definitiva, de lo que se trata es de preguntarse si el derecho a cambiar de nacionalidad incluye el derecho a renunciar a la nacionalidad que se posee ${ }^{63}$. Hay quienes han afirmado que tal derecho existe ${ }^{64}$. Incluso, yendo más allá, una posición más antigua sostenía que el derecho a la nacionalidad tornaba obligatoria la supresión de la anterior nacionalidad luego de la adquisición de una nueva ${ }^{65}$. Esta última posición es difícilmente defendible hoy. Sin embargo, la posición que admite que existe un derecho

${ }^{60}$ Las víctimas del caso podían clasificarse en dos grupos (en lo que se refiere al derecho a la nacionalidad). Por un lado, aquellas que, a pesar de reunir los requisitos establecidos por la legislación interna o el Derecho Internacional para la obtención de la nacionalidad dominicana, no habían visto reconocida esta nacionalidad. Por otro lado, aquellas que sí tenían formalmente reconocida la nacionalidad dominicana pero respecto de las cuales la violación del derecho a la nacionalidad se daba por la falta de efectividad de ese reconocimiento (porque los funcionarios públicos se negaban a tomar en cuenta los documentos que las acreditaban como dominicanas o directamente destruían esos documentos).

${ }^{61}$ Corte IDH, Personas dominicanas y haitianas expulsadas, párr. 319-325.

${ }^{62}$ El derecho a cambiar de nacionalidad aparece también en el artículo 15 de la Declaración universal de los Derechos Humanos.

63 Tal reclamación sería teóricamente posible incluso en ausencia de adquisición de una nueva nacionalidad, pero el caso obviamente es de laboratorio. La European convention on nationality obliga a los Estados a aceptar la renuncia a la nacionalidad siempre que ella no deje al individuo en situación de apatridia, aunque los Estados pueden disponer que la renuncia solo será efectiva en relación con sus nacionales que residen regularmente en el extranjero (artículo 8).

${ }^{64}$ Una respuesta positiva, en relación con el derecho a cambiar de nacionalidad en general y no en el contexto particular americano, en Ganczer, M., "The Right to a Nationality as a Human Right?", p. 18.

${ }^{65}$ En relación con el derecho a cambiar de nacionalidad en general y no en el contexto particular americano, Griffin, W.L. "The Right to a Single Nationality”, en Temple Law Quarterly, volumen 40, 1966, p. 58. 
a renunciar a la nacionalidad que se posee nos parece viable en el contexto americano, siempre por supuesto que se trate de una renuncia que se hace junto con la adquisición de una nueva nacionalidad. La Declaración y la Convención americanas no se refieren al derecho a adquirir una nueva nacionalidad (que se acumularía a la anterior), sino al derecho a cambiar de nacionalidad. Y cambiar es, precisamente, dejar una cosa para tomar otra.

Diferente es la solución jurídica del supuesto inverso, es decir, la de un individuo que adquiere una nueva nacionalidad y que pretende, en contra de la voluntad del Estado de su antigua nacionalidad, conservar la nacionalidad previa. Aunque hay quienes propician, en el plano teórico, el reconocimiento de un derecho a la múltiple nacionalidad ${ }^{66}$, no creemos que tal sea la solución en el plano de la normativa interamericana hoy vigente. La Comisión Interamericana ha dicho que la privación de la nacionalidad originaria por adquisición de una nueva realizada de acuerdo con la ley vigente al producirse tal adquisición es legítima ${ }^{67}$. Y cuando ha afirmado que el derecho a la nacionalidad también incluye la doble nacionalidad lo ha hecho en el contexto de un derecho interno que admitía la acumulación ${ }^{68}$ (el Estado solo actuaría ilegalmente si al retirar la nacionalidad a quien adquiere otra lo hace en contra de su propia legislación).En el estado actual del derecho americano no existe un rechazo a la nacionalidad múltiple, pero tampoco un derecho a acumular nacionalidades en contra de la voluntad del Estado interesado.

Por supuesto, ningún Estado está obligado a naturalizar extranjeros. A causa de que el otorgamiento de la nacionalidad cae dentro de las competencias del Estado soberano, este puede establecer cuáles son los requisitos que deben cumplir los extranjeros que aspiren a obtener la naturalización. Los Estados gozan a este respecto de un amplio margen de apreciación ${ }^{69}$. El Estado que concede la naturalización está llamado a apreciar en qué medida existen las condiciones que garanticen que el aspirante a obtenerla esté efectivamente vinculado con el sistema de valores e intereses de la sociedad a la que pretende pertenecer plenamente. Por ejemplo, resulta razonable que se exija que quien solicita la naturalización demuestre que sabe hablar, escribir y leer el idioma nacional, y que se haga un examen concerniente a la historia y la cultura del país ${ }^{70}$.

66 Spiro, P. J., "Dual Citizenship as a Human Right", en International Journal of Constitutional Law, volumen 8(1), 2010, pp. 111-130. Ver también, Spiro, P. J., "Dual Nationality and the Meaning of Citizenship”, en Emory Law Journal, vol. 46, 1997, pp. 1411-1485.

${ }^{67}$ Lo que implica que los instrumentos interamericanos no reconocen un derecho a la doble nacionalidad. Comisión IDH, Robelo González. La European convention on nationality, en cambio, obliga a los Estados a respetar la situación de doble nacionalidad en caso de adquisición originaria o por matrimonio (en otras palabras, les prohíbe en tales casos declarar perdida la nacionalidad previa). En los demás casos, permite que los Estados decidan (artículos 14 y 15).

${ }^{68}$ Comisión IDH, Caso Estiverne, resolución no. 20/88, caso 9855 (Haití), 24 de marzo de 1988. Comisión IDH, Serrano Sáenz, caso 12.525, informe no. 84/09, caso 12525 (Ecuador), 6 de agosto de 2009, párr. 65.

69 Corte IDH, Propuesta de modificación a la Constitución política de Costa Rica relacionada con la naturalización, párr. 62.

${ }^{70}$ Corte IDH, Propuesta de modificación a la Constitución política de Costa Rica relacionada con la naturalización, párr. 63. 


\section{LIMITADA OPERATIVIDAD DEL PRINCIPIO DE NO DISCRIMINACIÓN}

El principio de igualdad y no discriminación constituye un elemento fundamental de los sistemas internacionales de protección de los Derechos Humanos. La Convención Americana tiene dos disposiciones referidas a él: el artículo 1.1, que establece la igualdad en los derechos por ella consagrados; y el artículo 24, que establece la igualdad ante la ley ${ }^{71}$. El principio determina que los Estados, al regular los mecanismos de adquisición, cambio y pérdida de la nacionalidad, deben abstenerse de producir regulaciones discriminatorias o que tengan efectos discriminatorios ${ }^{72}$. También respecto de la aplicación de este principio resulta que el Derecho Internacional de los Derechos Humanos, aunque ha morigerado el rigor de la discrecionalidad estatal, no ha socavado los cimientos del régimen internacional de la nacionalidad.

La cuestión que se presenta aquí es, en efecto, que las bases de discriminación prohibidas ("raza, color, sexo, idioma, religión, opiniones políticas o de cualquier otra índole, origen nacional o social, posición económica, nacimiento o cualquier otra condición social”, según el artículo 1.1 de la Convención) están estrechamente vinculadas con los criterios tradicionalmente utilizados para determinar la adquisición de la nacionalidad. La Convención prohíbe la discriminación por nacimiento, pero resulta que el lugar de nacimiento sirve para la determinación de la nacionalidad por ius soli (criterio que hasta la propia Convención recepta). La Convención prohíbe la discriminación por raza y color, pero la transmisión de la nacionalidad por ius sanguinis (criterio generalmente admitido como lícito en Derecho Internacional) implica la aceptación de que la conformación del cuerpo nacional puede estar asociada a criterios étnicos ${ }^{73}$. La Convención prohíbe la discriminación por idioma, pero como hemos visto la jurisprudencia interamericana acepta que se ponga como requisito para la naturalización del extranjero que este hable el idioma nacional. La Convención prohíbe la discriminación por posición económica, pero muchas veces la legislación nacional exige demostrar que se poseen determinados medios de vida como paso previo a la naturalización.

${ }^{71}$ De este modo, el artículo 1.1 ha de leerse en correspondencia con los artículos sustantivos de la Convención que reconocen derechos, mientras que el artículo 24 tiene una existencia independiente e impone la igualdad en relación con el derecho interno. Entre muchos otros: Corte IDH, Comunidad Indígena Xákmok Kásek vs. Paraguay, fondo, reparaciones y costas, sentencia de 24 de agosto de 2010, Serie C no. 214, párr. 272; Corte IDH, Nadege Dorzema y otros vs. República Dominicana, fondo, reparaciones y costas, sentencia de 24 de octubre de 2012, Serie C No. 251, párr. 126; Corte IDH, Vélez Loor vs. Panamá, excepciones preliminares, fondo, reparaciones y costas, sentencia de 23 de noviembre de 2010, Serie C No. 218, párr. 253; Corte IDH, Apitz Barbera y otros (Corte Primera de lo Contencioso Administrativo) vs. Venezuela, excepción preliminar, fondo, reparaciones y costas, sentencia de 5 de agosto de 2008, Serie C No. 182, párr. 209.

72 Corte IDH, Niñas Yean y Bosico, párr. 141; Corte IDH, Personas dominicanas y haitianas expulsadas, párr. 264.

${ }^{73}$ Nótese en este sentido que la Convención para la eliminacion de todas las formas de discriminacion racial, Nueva York, 7 de marzo de 1966, UNTS vol. 660, no. I-9464, establece que ninguna de sus cláusulas “podrá interpretarse en un sentido que afecte en modo alguno las disposiciones legales de los Estados partes sobre nacionalidad, ciudadanía o naturalización, siempre que tales disposiciones no establezcan discriminación contra ninguna nacionalidad en particular" (artículo 1.3). 
La idea general que subyace a la interpretación de la Corte Interamericana es que no toda distinción basada en alguno de los criterios arriba mencionados es ilícita, sino que debe estudiarse su razonabilidad en el caso concreto. Ahora bien, solo en relación con determinadas bases de distinción sospechosas parece jugar el principio de no discriminación con cierta fuerza. Tal es el caso del sexo y de algunas situaciones que cabrían en la categoría de cualquier otra condición social. Quizá el criterio de distinción que la Corte ha evaluado más estrictamente es el basado en el sexo ${ }^{74}$. En su opinión consultiva respecto de las reformas a la Constitución de Costa Rica en materia de nacionalidad, la Corte declaró que no era conforme al principio de igualdad establecer un mecanismo privilegiado de naturalización en favor de la mujer que casara con costarricense, pero no del hombre que casara con costarricense ${ }^{75}$.

En la misma opinión la Corte se refirió a las distinciones en materia de nacionalidad basadas en la nacionalidad previa (que podría caber, eventualmente, en la categoría de discriminación por cualquier otra condición social). Para la Corte, no resulta discriminatorio fijar requisitos menos exigentes para la naturalización (por ejemplo, en relación con el tiempo de residencia) respecto de personas que por su nacionalidad de origen tienen vínculos más estrechos con el Estado en el que desean nacionalizarse. Sin embargo, para que la distinción basada en la nacionalidad previa sea legítima es necesario que ella sea razonable. Así, se juzgó razonable que Costa Rica estableciera criterios de naturalización más flexibles para centroamericanos, iberoamericanos y españoles de origen ${ }^{76}$.

Por último, la Corte también se ha referido a la relación entre adquisición de nacionalidad y estatus migratorio (que también podría caber, eventualmente, en la categoría de discriminación por cualquier otra condición social). Ella ha afirmado que el estatus migratorio de una persona no puede ser condición para el otorgamiento de la nacionalidad por el Estado ${ }^{77}$, ya que según ha dicho la Corte de modo general, la calidad

${ }^{74}$ Desde hace varias décadas ha suscitado particular preocupación la situación de la mujer que, al casarse con un extranjero, pierde su nacionalidad. Esta pérdida se funda sobre el presupuesto de que, al contraer matrimonio, la mujer adquiere la nacionalidad del marido. Este régimen somete a la mujer, en el mejor de los casos, a la adquisición forzosa de una nacionalidad; y en el peor, a una situación de apatridia, si la ley del marido no prevé tal adquisición. La Convención sobre la nacionalidad de la mujer casada, Nueva York, UNTS vol. 309, no. I-4468, prevé que ni la celebración o disolución del matrimonio, ni el cambio de nacionalidad del marido durante el mismo, deben afectar la nacionalidad de la mujer (artículos 1 y 2), sin perjuicio de la obligación de los Estados de establecer mecanismos preferentes de adquisición de la nacionalidad del marido, siempre sobre una base voluntaria (artículo 3). Igualmente, la Convención sobre la eliminación de todas las formas de discriminación contra la mujer, establece la igualdad de derechos entre el hombre y la mujer en materia de nacionalidad, prohíbe que el matrimonio tenga efecto automático sobre la nacionalidad de la mujer y establece que los Estados deben otorgar a la mujer los mismos derechos que al hombre respecto de la nacionalidad de sus hijos (artículo 9). En el ámbito americano, ya hemos citado en la sección 3 de este trabajo la Convención sobre la nacionalidad de la mujer, con disposiciones similares.

75 Corte IDH, Propuesta de modificación a la Constitución política de Costa Rica relacionada con la naturalización, párr. 64-67.

76 Corte IDH, Propuesta de modificación a la Constitución política de Costa Rica relacionada con la naturalización, párr. 60.

${ }^{77}$ Corte IDH, Niñas Yean y Bosico, párr. 156. Corte IDH, Personas dominicanas y haitianas expulsadas, párr. 264. 
migratoria no puede constituir, de ninguna forma, una justificación para privar a una persona del goce y ejercicio de sus derechos ${ }^{78}$. Esta afirmación no es totalmente clara. Es seguro que la calidad migratoria no puede constituir un obstáculo a la adquisición de la nacionalidad según las concretas normas de Derecho Internacional que obligan a un Estado a otorgar la nacionalidad para evitar que la persona resulte apátrida (derecho concreto a la nacionalidad). Sin embargo, interpretar en toda su amplitud esta afirmación de la Corte llevaría a sostener que en todo proceso de adquisición de la nacionalidad (incluso por modo derivado) los Estados no podrían distinguir entre personas en situación regular y personas en situación irregular en su territorio. Así, por ejemplo, los Estados estarían obligados a dar la nacionalidad a las personas que hubiesen residido el tiempo requerido en el territorio, incluso si esta permanencia fue de modo irregular. Esta última interpretación no es consistente con las reglas básicas del Derecho Internacional en materia de nacionalidad.

La Corte también ha dicho que el estatus migratorio de una persona no se transmite a sus hijos ${ }^{79}$. Esta afirmación, tomada en sentido lato, resulta correcta. Sin embargo, esto no se debe confundir con el hecho de que la situación migratoria de los padres pueda afectar en algunos casos la situación de los hijos en relación con el derecho a la nacionalidad. De hecho, en las mismas sentencias en la que la Corte realiza la afirmación acerca de la transmisión del estatus migratorio admite que el carácter de extranjeros en tránsito de los padres puede resultar una justa excepción al principio del ius soli en la adquisición de la nacionalidad. Es verdad que en los casos dijo también que la aplicación concreta de esa excepción fue arbitraria, y sostuvo que la excepción no podría aplicarse cuando entra en juego el ius soli para evitar una situación de apatridia. Sin embargo, no negó el principio de que la situación migratoria de los padres (su carácter de extranjeros en tránsito) resulta una causal legítima para denegar la adquisición de la nacionalidad por ius soli.

\section{Conclusiones}

A lo largo del presente artículo hemos abordado la hipótesis según la cual la evolución del derecho americano en el campo de la nacionalidad ha seguido la evolución general del Derecho Internacional. Así, los instrumentos convencionales de las primeras décadas del siglo XX adoptan una perspectiva estatalista, dando prueba del interés de los Estados por solucionar los conflictos de nacionalidad en el continente. El advenimiento de la era de los Derechos Humanos cambia, aunque solo parcialmente, el enfoque. El Derecho Internacional de los Derechos Humanos introduce un interés de protección del individuo sin negar sin embargo el principio fundamental de la soberanía en la determinación de quiénes son nacionales de un Estado.

${ }^{78}$ Corte IDH, Condición jurídica y derechos de los migrantes indocumentados, opinión consultiva OC-18/03 de 17 de septiembre de 2003, Serie A No. 18, párr. 134.

${ }^{79}$ Corte IDH, Niñas Yean y Bosico, párr. 156; Corte IDH, Personas dominicanas y haitianas expulsadas, párr. 264. 
El Derecho Internacional de los Derechos Humanos morigera la potestad del Estado de determinar quiénes son sus nacionales, pero no altera el elemento que constituye la piedra de toque de todo el régimen internacional de la nacionalidad: la determinación de los criterios de adquisición, cambio y pérdida de una nacionalidad es una cuestión de legislación interna. Es verdad que el Derecho Internacional de los Derechos Humanos ha reconocido un derecho subjetivo a la nacionalidad, pero tal derecho opera dentro de los márgenes de la legislación nacional (así, no obliga a un Estado a otorgar su nacionalidad bajo un determinado criterio, solo impone que la interpretación y aplicación de las normas internas se haga bajo parámetros de razonabilidad y respeto de las reglas del Estado de derecho). Algo parecido sucede con la privación de nacionalidad: el Derecho Internacional de los Derechos Humanos no le dice al Estado en qué casos ha de privar de nacionalidad a alguien, solo le impone el límite de que, sea cuales fueren los supuestos de privación de nacionalidad de la legislación interna, ellos no sean arbitrarios.

Desde luego que estos cambios no son banales y suponen un avance en el reconocimiento del valor central de la nacionalidad en la vida del individuo. Pero, insistimos, no alteran el principio central de soberanía estatal en esta materia, aunque lo suavicen. Esto es particularmente claro si se analiza la aplicación del principio de no discriminación en relación con la nacionalidad. Distinciones que en otros campos resultarían inaceptables son perfectamente posibles en relación con la nacionalidad. Así, por ejemplo, una norma que estableciera que solo pueden estudiar en las universidades quienes sean hijos de antiguos estudiantes universitarios sería seguramente descalificada por constituir una discriminación sobre la base del nacimiento. Pero una norma que establece que son nacionales los hijos de los nacionales es perfectamente lícita.

La restricción más importante que se impone a los Estados es la obligación de otorgar la nacionalidad a los nacidos en su territorio que resultarían de otro modo apátridas. A diferencia del derecho genérico a la nacionalidad, este derecho concreto establece un mecanismo específico de adquisición de una nacionalidad. Este es sin dudas un elemento positivo en la lucha contra la apatridia. También resulta positivo el espíritu liberal con el que la Corte y la Comisión Interamericana han abordado la problemática de la nacionalidad. Aunque algunos aspectos interpretativos permanecen todavía oscuros, esta labor ha permitido aclarar en buena medida los alcances de la normativa interamericana.

\section{BIBLIOGRAFÍA}

Arlettaz, F., "La nacionalidad en el Derecho Internacional americano", en Anuario Mexicano de Derecho Internacional, vol. XV, 2015, pp. 413-447.

Arlettaz, F., Extranjeros e inmigrantes: cuatro problemas de Derecho Internacional y Filosofía Jurídica, Lex Nova, Madrid, 2015.

Balladore-Pallieri, G., La natura giuridica internazionale della potestà dello stato sugli individui, Torino, 1932.

Bisschop, W.R., "Nationality in International Law", en The American Journal of International Law, vol. 37(2), 1943, pp. 320-325.

Corriente, J.A., "La nacionalidad de las personas físicas ante el derecho internacional", en Anuario de Derecho Internacional, vol. I, 1974, pp. 223-247. 
De Groot, G.-R., "Survey on Rules on Loss of Nationality in International Treaties and Case Law", en CEPS Papers on Liberty and Security in Europe, vol. 57, 2013, pp. pp. 1-27.

GANCZER, M., "The Right to a Nationality as a Human Right?", en Hungarian Yearbook of International Law and European Law, 2014, p. 15-33.

Griffin, W.L. "The Right to a Single Nationality”, en Temple Law Quarterly, vol. 40, 1966, p. $57-65$.

Hailbronner, K., "Nationality", en Aleinikoff, T. A., Chetail, V., Migration and International Legal Norms, Asser Press, La Haya, 2003.

LANFRANCHI, M.-P., "Les notions de nationalité et citoyenneté interrogées par le Droit International Public”, en Lanfranchi, M.-P. et al. (dir.), Nationalité et citoyenneté, Bruylant, Bruxelles, 2012.

Lavopa, F., "Artículo 20. Derecho a la nacionalidad", en Alonso Regueira, E. (coord.), La Convención Americana de Derechos Humanos y su proyección en derecho argentino, Universidad de Buenos Aires, Buenos Aires, 2013, p. 333-353.

Locke, J., Second Treatise on Government, Harlan Davidson, Illinois, [1689]1982.

Makarov, A.N., "Règles générales du droit de la nationalité", en Recueil des Cours, vol. 74, 1949 , pp. 273 y ss.

O’Donnell, D., Derecho Internacional de los Derechos Humanos, México, Oficina del Alto Comisionado de las Naciones Unidas para los Derechos Humanos, 2012.

Perrin, G., "Les conditions de validité de la nationalité en Droit International Public", en Recueil d'Études de Droit International en Hommage à Paul Guggenheim, Ginebra, 1968, pp. 853-888.

RodríGuez, M.F., "El derecho a la nacionalidad”, en Revista Internacional de Derechos Humanos, vol. 1, 2011, p. 81-107.

SLOANE, R.D., "Breaking the Genuine Link: The Contemporary International Regulation of Nationality", en Harvard International Law Journal, vol. 50(1), 2009, pp. 1-60.

SpIRo P.J., "An Emerging International Law of Citizenship?", en American Society of International Law Proceedings, vol. 101, 2007, pp. 89-91.

SPIRo, P.J., "Dual Citizenship as a Human Right", en International Journal of Constitutional Law, volumen 8(1), 2010, pp. 111-130.

SPIro, P.J., "Dual Nationality and the Meaning of Citizenship", en Emory Law Journal, vol. 46, 1997, pp. 1411-1485.

VAN Panhuys, H.F., The role of nationality in International Law: an outline, Leyden, 1969.

VATtel, E., Le droit des gens, ou príncipes de la loi naturelle appliqués à la conduite et aux affaires des nations, Société Typographique, Neuchatel, 1773. 
